\title{
A EVOLUÇÃO DAS EMISSÕES VEICULARES NO ESTADO DE SÃO PAULO COM A INCLUSÃO DAS EMISSÕES DE ABASTECIMENTO, NO PERÍODO DE 2006 A 2014
}

\author{
Cristiane Dias $^{1}$; Marcelo Pereira Bales ${ }^{1}$ e Silmara Regina da Silva ${ }^{1}$ \\ ${ }^{1}$ CETESB (Companhia Ambiental do Estado de São Paulo)

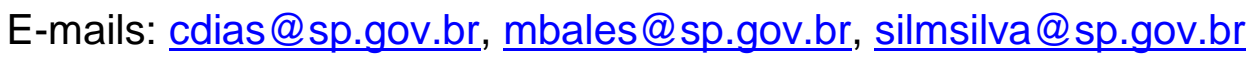

\section{RESUMO}

As estimativas de emissões veiculares publicadas anualmente pela CETESB são baseadas nas metodologias já conhecidas e publicadas nas duas edições do Inventário Nacional de Emissões Atmosféricas por Veículos Automotores Rodoviários [1], [2] e pelo Painel Intergovernamental de Mudanças Climáticas [3]. O objetivo deste trabalho é apresentar e discutir as estimativas de emissões veiculares para o Estado de São Paulo, utilizando a metodologia publicada nos relatórios da CETESB, incluindo as emissões provenientes do abastecimento dos veículos, que oferecem significativo impacto nas emissões dos compostos orgânicos voláteis (COV). A partir de 2015, as emissões de abastecimento dos veículos do ciclo Otto serão incorporadas às emissões de escapamento e evaporativas. O período em estudo também foi ampliado de 2006 a 2014. Dependendo das condições atmosféricas, os COV podem reagir com os óxidos de nitrogênio, formando o ozônio na troposfera terrestre. Nesse nível da atmosfera, o ozônio torna-se um poluente tóxico, que apresenta impactos negativos à saúde humana e à qualidade do ar. Atualmente, a CETESB [4] inclui no seu inventário de emissões de fontes móveis apenas as emissões do veículo e não do seu abastecimento. 


\section{INTRODUÇÃO}

As estimativas de emissões veiculares publicadas anualmente pela CETESB são baseadas nas metodologias publicadas nas duas edições do Inventário Nacional de Emissões Atmosféricas por Veículos Automotores Rodoviários [1], [2] e pelo Painel Intergovernamental de Mudanças Climáticas [3]. Essas metodologias demonstram que as emissões veiculares são fundamentalmente dependentes dos fatores de emissão, da intensidade de uso ou quilometragem anual do veículo e do consumo de combustíveis da área ou região de interesse.

A equação geral de cálculo das emissões veiculares é a equação 1:

$$
E=F e \times F r \times l u
$$

Onde:

- E é a taxa anual de emissão do poluente considerado (g/ano);

- Fe é o fator de emissão do poluente considerado. É específico para cada tipo de veículo, idade e combustível utilizado. É expresso em massa de poluentes emitida por quilômetro percorrido $\left(\mathrm{g}_{\text {poluente }} / \mathrm{km}\right)$;

- Fr é a frota de veículos circulante para cada tipo de veículo, idade e combustível considerado. É expressa em número de veículos; e

- Iu é a intensidade de uso do veículo. É específico para cada tipo e idade do veículo, expressa em quilometragem anual percorrida (km/ano).

Os fatores de emissão por categoria/combustível e poluente são provenientes dos RVEP (Relatório de Valores de Emissão de Produção), elaborados com a finalidade de acompanhamento do PROCONVE/PROMOT. Resultam da média ponderada de ensaios de emissões dos modelos de veículos novos mais vendidos. No caso dos automóveis e comerciais leves do ciclo Otto, os fatores de emissão são corrigidos por curvas de deterioração que incrementam os fatores de emissão, conforme avança a quilometragem acumulada do veículo. Essas curvas dependem também do ano de fabricação do veículo. Há uma curva diferente para cada ano ou intervalo. Os fatores de emissão de motocicletas e veículos pesados não são corrigidos pela ausência de curvas de deterioração para esses segmentos no Brasil.

Os valores de vendas anuais de veículos novos, leves e pesados, foram fornecidos pela ANFAVEA [5] (Associação Nacional dos Fabricantes de Veículos Automotores) para o Estado de São Paulo e a ABRACICLO [6] (Associação Brasileira dos Fabricantes de Motocicletas, Ciclomotores, Motonetas, Bicicletas e Similares) disponibilizou os valores correspondentes às motocicletas. 
A intensidade de uso de referência representa a distância percorrida por ano e por tipo de veículo. Esta variável apresenta uma grande incerteza, em uma frota diversificada, em que cada categoria possui um perfil próprio de utilização. Desta forma, a variável intensidade de uso de referência precisa ser ajustada em função do consumo de combustíveis observado no Estado ou região de interesse, pois essas variáveis, a distância percorrida e o consumo observado são diretamente proporcionais.

Foram empregadas estimativas de intensidade de uso de referência por categoria, variando em função da idade do veículo e publicadas em CETESB [7]. A partir dos valores de intensidade de uso de referência e do volume de combustíveis consumidos no Estado de São Paulo foi realizado o ajuste da intensidade de uso.

As emissões de hidrocarbonetos não metano ( $\mathrm{NMHC}$ ) provenientes do abastecimento de veículos foram adicionadas às emissões totais NMHC já estimadas anteriormente. Deste modo, as emissões veiculares de NMHC passam a incluir, além das emissões de escapamento e evaporativas, também as emissões de abastecimento. Estas emissões contribuem significativamente nas emissões de compostos orgânicos voláteis (COV), que incluem os $\mathrm{NMHC}$ e os aldeídos totais (RCHO), formado pelos compostos formaldeído e acetaldeído.

Dependendo das condições atmosféricas, os COV podem reagir com os óxidos de nitrogênio $\left(\mathrm{NO}_{\mathrm{x}}\right)$, formando o ozônio $\left(\mathrm{O}_{3}\right)$ na troposfera terrestre. Nesse nível da atmosfera, o ozônio torna-se um poluente tóxico, que apresenta impactos negativos à saúde humana e à qualidade do ar.

A Região Metropolitana de São Paulo (RMSP) apresenta um alto potencial de formação de ozônio, uma vez que há grande emissão de precursores, principalmente de origem veicular. Segundo a CETESB, o ano de 2013 foi um dos anos com o menor número de dias com ultrapassagem do padrão do poluente ozônio (Padrão Estadual de $140 \mu \mathrm{g} / \mathrm{m}^{3}$ para 8 horas), provavelmente em função das variáveis meteorológicas. Porém, esse poluente ainda requer atenção e controle dos seus precursores.

\section{INFORMAÇÕES GERAIS}

Os poluentes inventariados foram o monóxido de carbono (CO), os hidrocarbonetos não metano (NMHC), incluindo as emissões evaporativas e as de abastecimento, os óxidos de nitrogênio $\left(\mathrm{NO}_{x}\right)$, o material particulado $(\mathrm{MP})$, o dióxido de enxofre $\left(\mathrm{SO}_{2}\right)$ e os aldeídos totais (RCHO). Foi estimada a emissão de dióxido de carbono equivalente, $\mathrm{CO}_{2 \text { eq, }}$, que equipara o potencial de aquecimento global dos Gases de Efeito Estufa (GEE) $\mathrm{CO}_{2}$, óxido nitroso e metano pelo conceito do potencial de aquecimento global (GWP). Não foram consideradas as emissões de $\mathrm{CO}_{2}$ oriundas 
dos combustíveis renováveis etanol hidratado, etanol anidro e biodiesel, de acordo com a metodologia de contabilização de GEE adotada na Política Estadual de Mudanças Climáticas do Estado, que segue a recomendação do IPCC (Painel Intergovernamental de Mudanças Climáticas) [3].

As emissões veiculares da maioria dos poluentes foram estimadas utilizando a abordagem "bottom-up", na qual se considera a distância anual percorrida pelo veículo, fatores de emissão e frota circulante para o cálculo das emissões. As exceções foram as estimativas de $\mathrm{CO}_{2}$ e $\mathrm{SO}_{2}$, para todas as categorias, e $\mathrm{CH}_{4}$ e $\mathrm{N}_{2} \mathrm{O}$, para o ciclo Diesel, onde foi empregada a abordagem "top-down", devido à ausência de fatores de emissão dos veículos. Nesse caso, utilizam-se fatores de emissão dos combustíveis e o consumo observado dos mesmos.

O objetivo deste trabalho é apresentar e discutir as estimativas de emissões veiculares para o Estado de São Paulo, utilizando a metodologia publicada nos relatórios da CETESB, incluindo as emissões provenientes do abastecimento dos veículos, que oferecem significativo impacto nas emissões dos COV. A partir de 2015, as emissões de abastecimento dos veículos do ciclo Otto serão incorporadas às emissões de escapamento e evaporativas. $O$ período em estudo também foi ampliado de 2006 a 2014.

Foram utilizadas taxas de evaporação da gasolina e do etanol recomendadas no estudo "Redução da Emissão Evaporativa do Veículo em Movimento e no Reabastecimento de Combustível" [8].

A tabela 1 apresenta as taxas de evaporação dos combustíveis comercializados no Brasil e adotadas neste trabalho.

Tabela 1 - Taxa de evaporação de combustíveis

\begin{tabular}{|l|r|}
\hline Combustivel & Taxa de evaporação $(\mathbf{g} / \mathbf{I})$ \\
\hline Gasolina & 1,14 \\
\hline Etanol & 0,37
\end{tabular}

Fonte: SZWARC [8], adaptado.

Os veículos que utilizam motores do ciclo Diesel não foram considerados, pois a volatilidade do óleo diesel é baixa e não existem estudos consideráveis sobre esse assunto. Pela falta de dados e estudos específicos e pelo menor consumo de combustível observado na categoria, não foi considerado o abastecimento de motocicletas. 
Para o cálculo das emissões de abastecimento foi utilizado o consumo total de gasolina C e etanol hidratado combustível no Estado de São Paulo, no período de 2006 a 2014. 


\section{FROTA CIRCULANTE}

A frota circulante do Estado de São Paulo, para o período de 2006 a 2014, é apresentada na figura 1. O número de automóveis do ciclo Otto é superior ao número de veículos do ciclo Diesel e de motocicletas. O crescimento da frota de veículos do ciclo Otto foi de $49 \%$ de 2006 a 2014, e as frotas circulantes do ciclo Diesel e de motocicletas apresentaram um aumento de $56 \%$ e $76 \%$ respectivamente.

Figura 1- Estimativa da frota circulante no Estado de São Paulo, de 2006 a 2014.

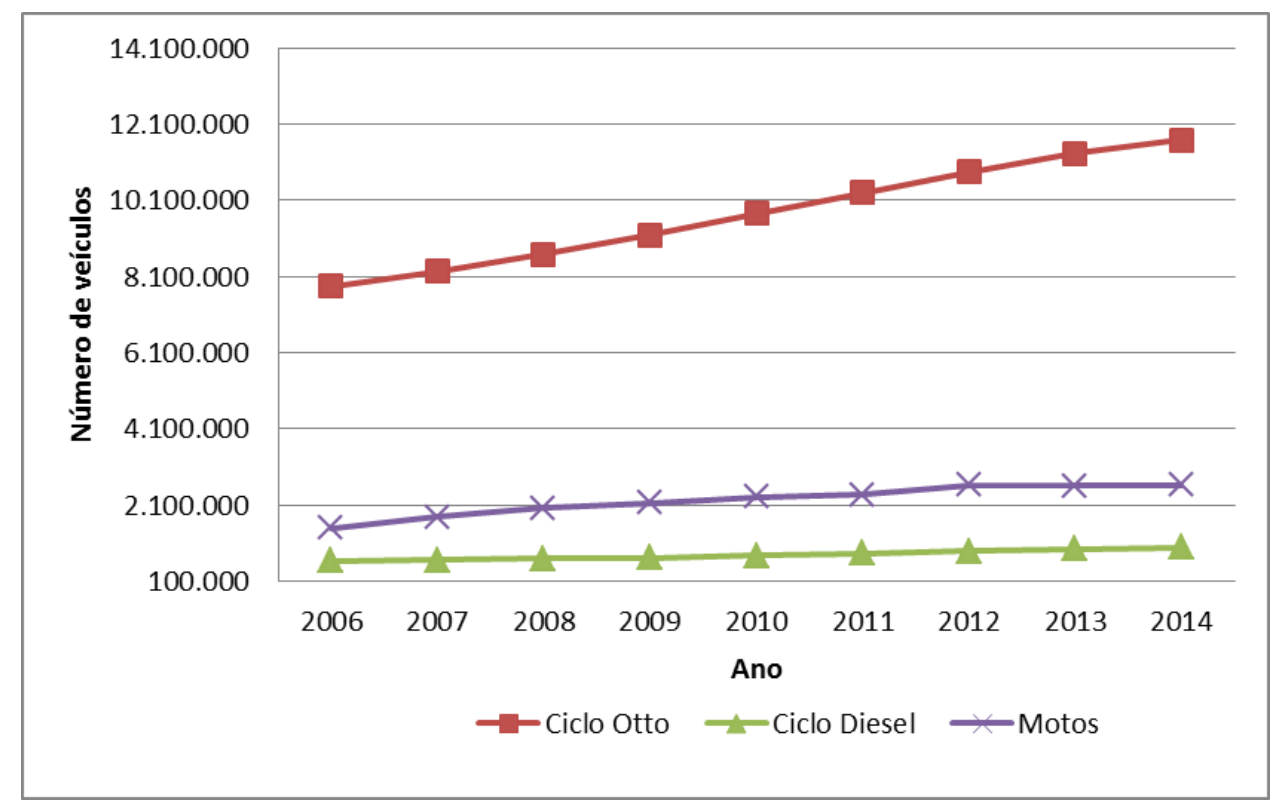

\section{CONSUMO DE COMBUSTÍVEL}

Para o cálculo das estimativas das emissões veiculares, foram utilizados os dados de consumo rodoviário de combustíveis fornecidos pela ANP (Agência Nacional do Petróleo, Gás Natural e Biocombustíveis) [9] e indicados na figura 2.

A intensidade de uso de referência ou quilometragem anual é uma das variáveis da equação 1 e deve ser ajustada pelo total de combustível consumido de Gasolina C, Etanol Hidratado e Óleo Diesel observado no Estado de São Paulo. 
Figura 2 - Consumo de combustíveis de uso rodoviário no Estado de São Paulo.

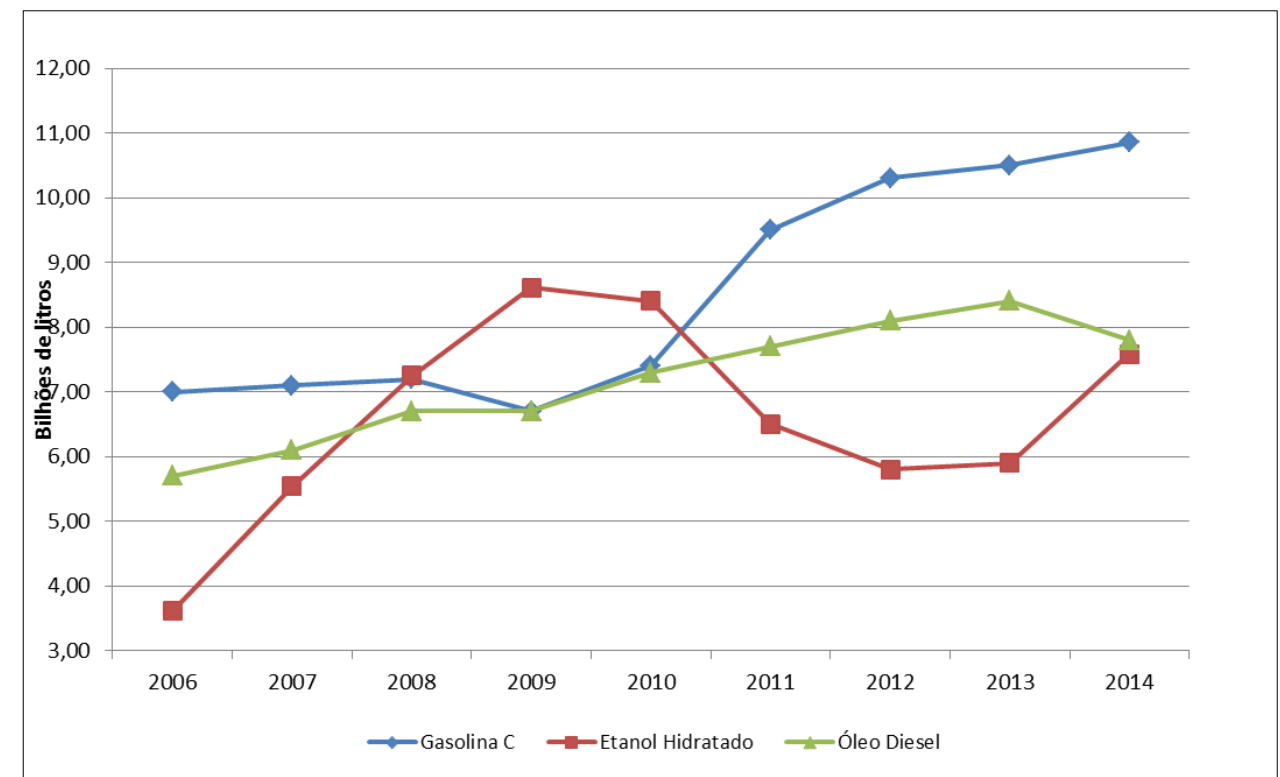

Fonte: Adaptado ANP[9]

Destaca-se no gráfico o aumento constante no consumo de gasolina e de diesel até o ano de 2013. Em 2014 houve pequena redução no consumo do diesel e aumento significativo no consumo de etanol hidratado.

\section{ANÁLISE DOS RESULTADOS}

A figura 3 indica a evolução do total das emissões de CO no Estado de São Paulo, em toneladas, de 2006 a 2014. Os veículos automotores do ciclo Otto são responsáveis pela maior parcela das emissões de $\mathrm{CO}$ e apresentaram uma redução de $43 \%$ nas emissões. As motocicletas apresentaram a redução de $14 \%$ e os veículos do ciclo Diesel tiveram a diminuição de $13 \%$ na emissão de CO nesse período. 
Figura 3 - Evolução das emissões de CO no Estado de São Paulo, de 2006 a 2014.

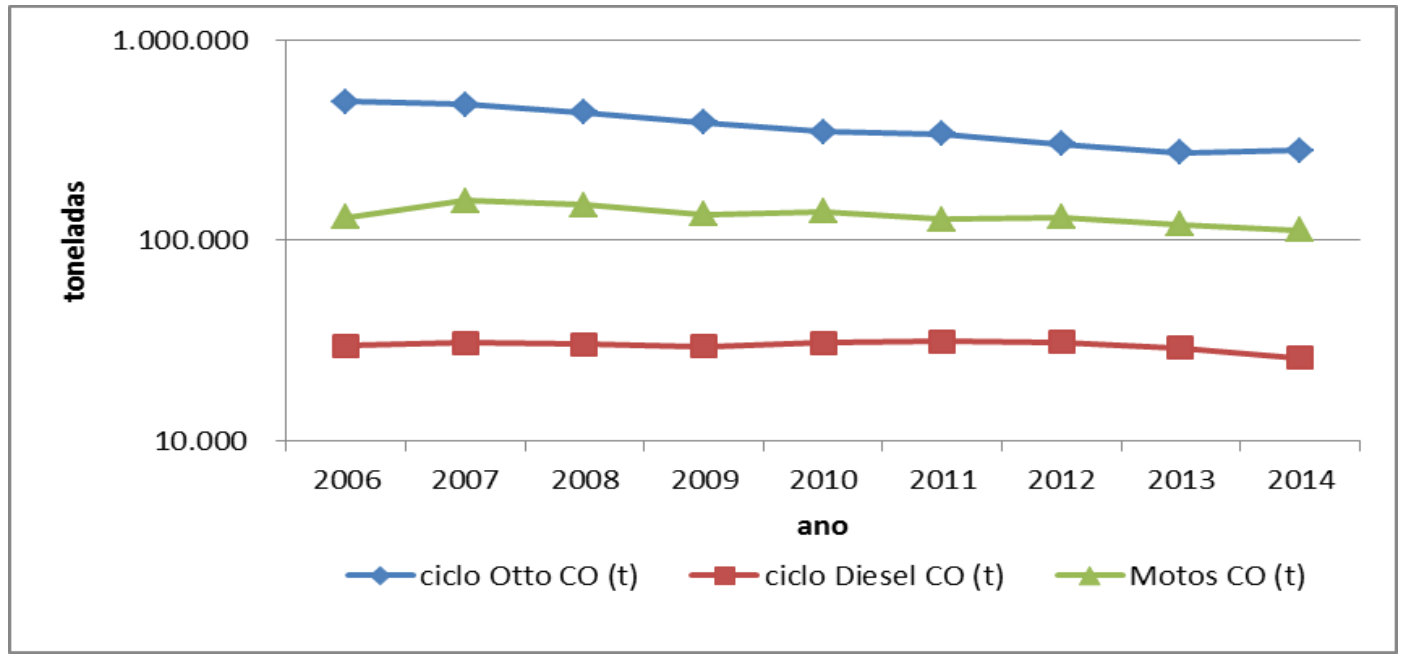

A figura 4 mostra a evolução das emissões de NMHC, considerando as emissões de escapamento, as evaporativas e de abastecimento para automóveis e comerciais leves do ciclo Otto, para o período de 2006 a 2014. Houve redução de 32\% nas emissões de NMHC do ciclo Otto e a redução de 33\% nas emissões de NMHC dos veículos do ciclo Diesel. As motocicletas indicaram a redução de $3 \%$ em suas emissões.

Figura 4 - Evolução das emissões de NMHC no Estado de São Paulo, de 2006 a 2014.

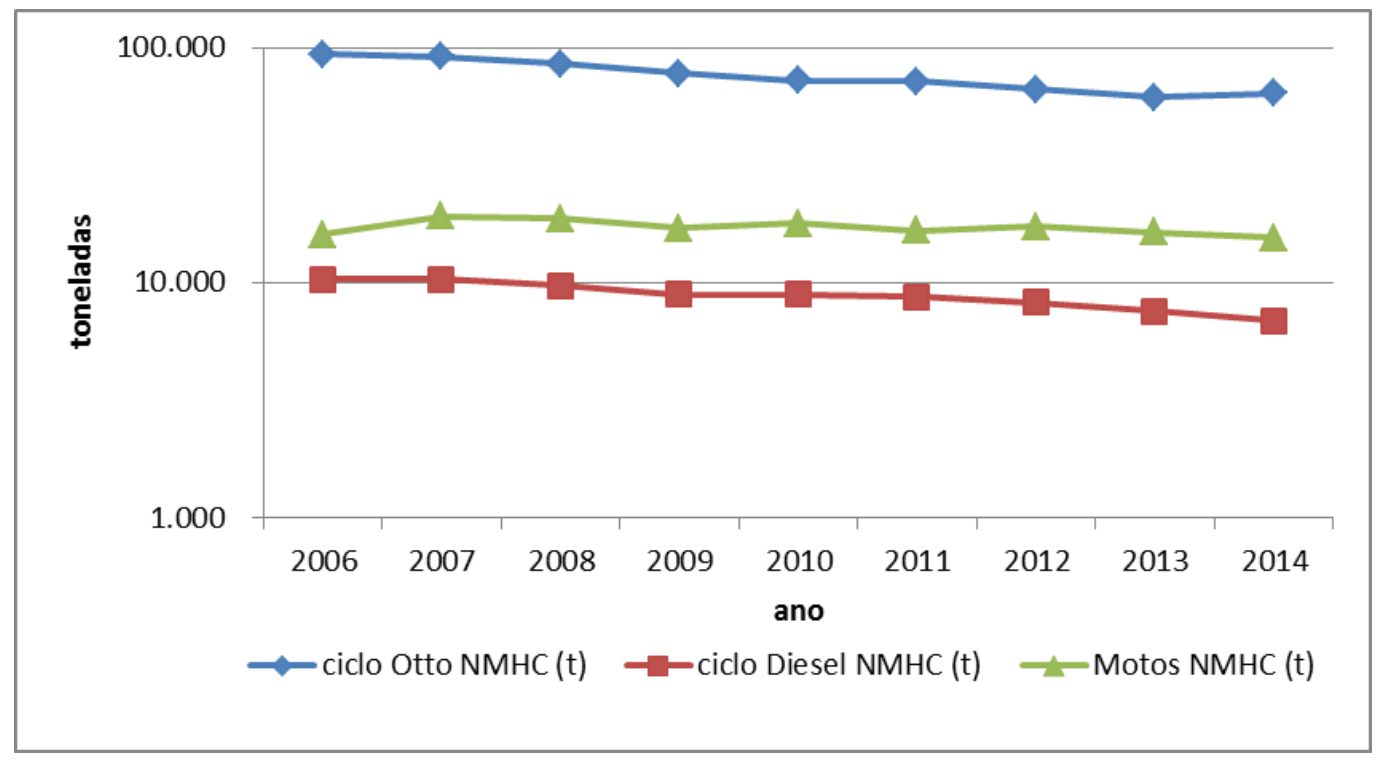


A figura 5 apresenta a evolução das emissões de NMHC (escapamento e evaporativas) e de abastecimento veicular, no período de 2006 a 2014. As emissões de NMHC de escapamento e as evaporativas diminuíram $41 \%$ porém as emissões de NMHC de abastecimento veicular aumentaram $58 \%$.

Figura 5 - Evolução das emissões de NMHC de escapamento e evaporativas e de NMHC do abastecimento veicular no Estado de São Paulo, de 2006 a 2014.

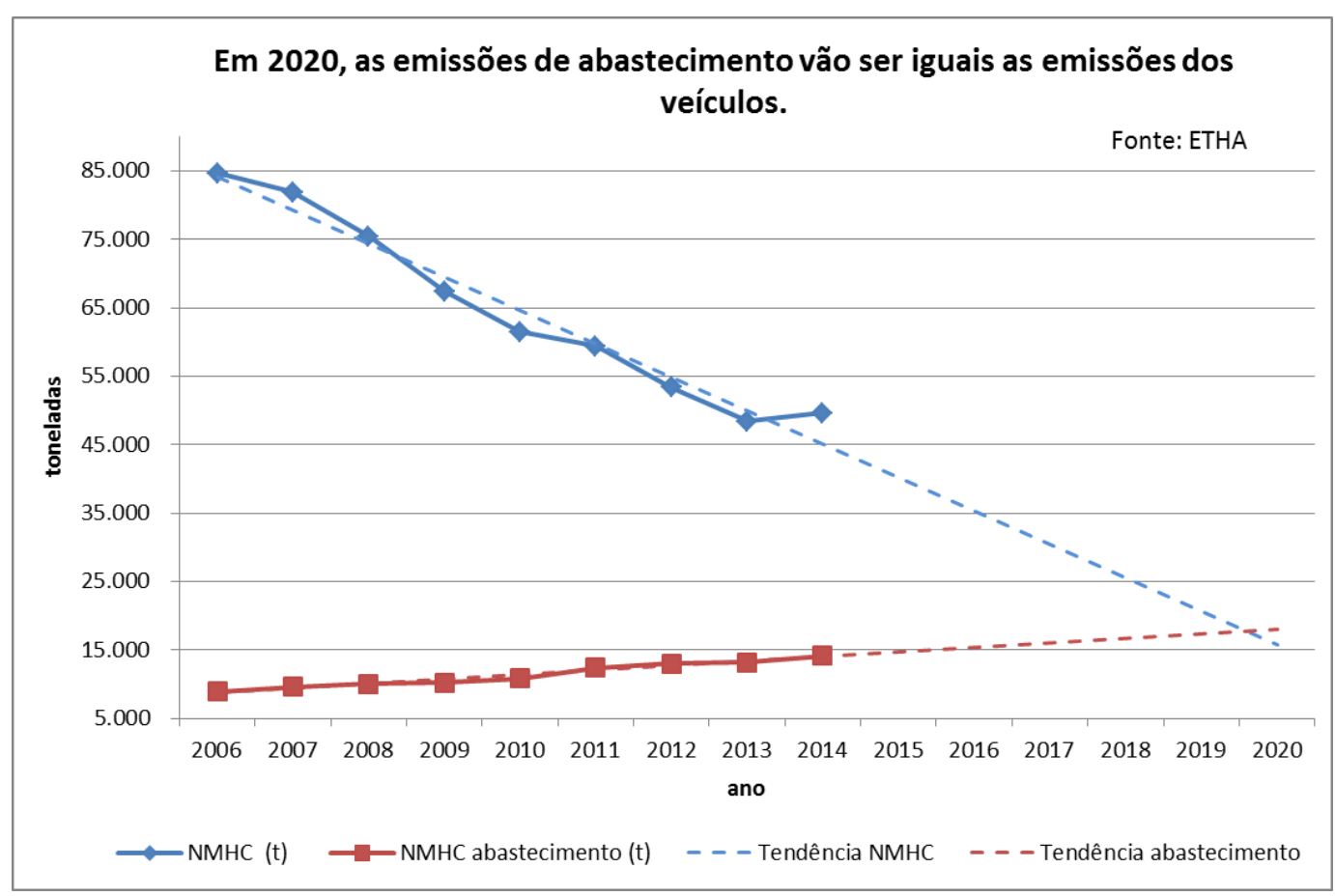

A tabela 2 mostra as porcentagens relativas ao abastecimento veicular nas emissões totais NMHC no Estado de São Paulo, no período de 2006 a 2014. 
Tabela 2 - Porcentagem relativa às emissões de abastecimento veicular, nas emissões de NMHC no Estado de São Paulo, no período de 2006 a 2014.

\begin{tabular}{|c|c|}
\hline Ano & Abastecimento Veicular (\%) \\
\hline 2006 & $10 \%$ \\
2007 & $11 \%$ \\
\hline 2008 & $12 \%$ \\
\hline 2009 & $13 \%$ \\
2010 & $15 \%$ \\
2011 & $17 \%$ \\
\hline 2012 & $20 \%$ \\
2013 & $21 \%$ \\
\hline 2014 & $22 \%$ \\
\hline
\end{tabular}

Os fenômenos de acréscimo e decréscimo das curvas acontecem por que as emissões de abastecimento aumentam em função direta do aumento do consumo de combustível e este varia em função da atividade econômica e do aumento da frota.

Por outro lado, a curva de emissão de NMHC tende a decrescer com o controle da emissão de NMHC de escapamento, que evolui em função da renovação natural da frota, na qual os veículos mais novos com fator de emissão menor em função do PROCONVE [10] passam a ser cada vez mais significativos.

Como ainda não existe controle da emissão de NMHC de abastecimento, a tendência é que essa emissão fique cada vez mais significativa na emissão total do poluente. Mantidas as tendências, no ano de 2020 os montantes emitidos se equivalerão, alcançando aproximadamente 20 mil toneladas cada um. A linha de tendência das emissões de NMHC (escapamento e evaporativa) deve apresentar um comportamento assintótico. A emissão de NMHC de escapamento tende à estabilização, devido ao processo de deterioração e ao aumento da frota circulante, se não houver a implantação de novas tecnologias de redução de emissão por novas fases do PROCONVE ou pela adoção de formas alternativas de motores a combustão (híbridos e/ou elétricos).

Como indica a figura 6 , os veículos do ciclo Diesel são os maiores responsáveis pelas emissões de $\mathrm{NO}_{x}$, com a redução de $14 \%$ em suas emissões. Para os veículos do ciclo Otto, houve a redução de 30\% nas emissões, de 2006 a 2014. As motocicletas aumentaram as suas emissões de $\mathrm{NO}_{\mathrm{x}}$. 
Figura 6 - Evolução das emissões de NOx no Estado de São Paulo, de 2006 a 2014.

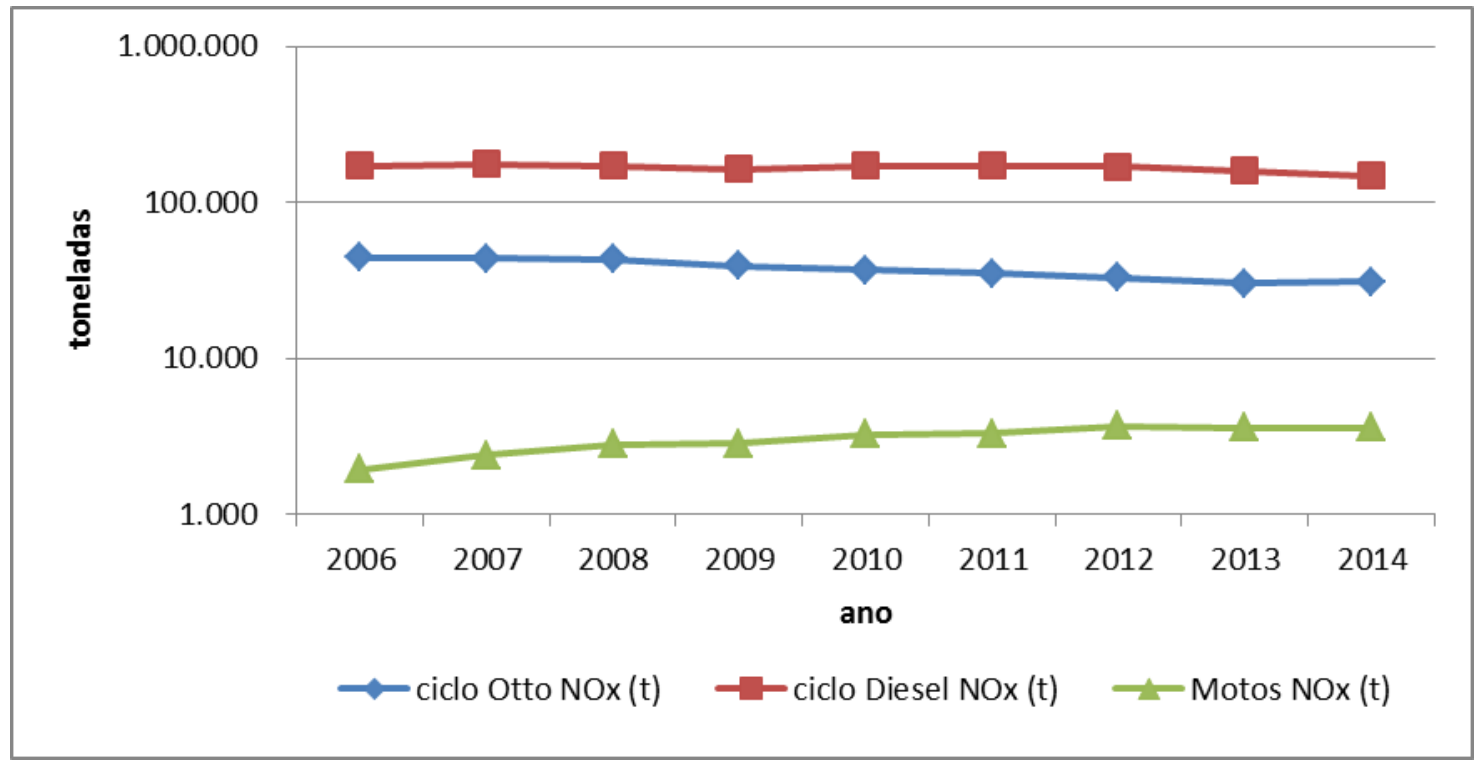

A figura 7 aponta que os veículos do ciclo Diesel também são os maiores responsáveis pelas emissões de MP no Estado, mas pode-se observar a redução de $35 \%$ nas emissões. Para os veículos do ciclo Otto, houve o aumento de $25 \%$, de 2006 a 2014. As motocicletas apresentaram a redução de 11\% das suas emissões no período.

Figura 7 - Evolução das emissões de MP no Estado de São Paulo, de 2006 a 2014.

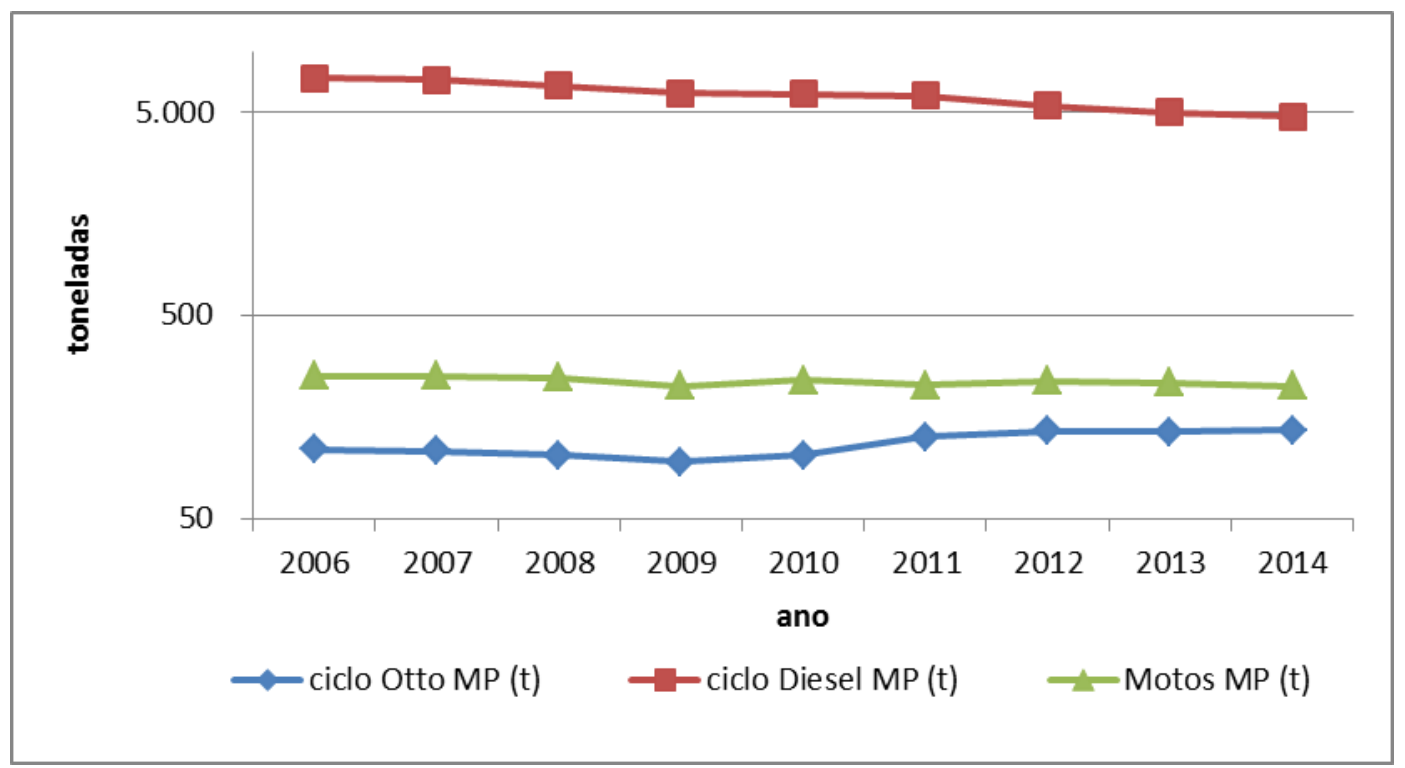


A figura 8 ilustra as emissões totais de $\mathrm{SO}_{2}$ dos veículos do ciclo Diesel, Otto e das motocicletas. Para o ciclo Diesel, observamos a redução $35 \%$ nas emissões de $\mathrm{SO}_{2}$. Para o ciclo Otto houve a redução de $78 \%$ nas emissões, de 2006 a 2014. As motocicletas apresentaram a redução de $65 \%$ das emissões neste período.

Figura 8 - Evolução das emissões de SO 2 no Estado de São Paulo, de 2006 a 2014.

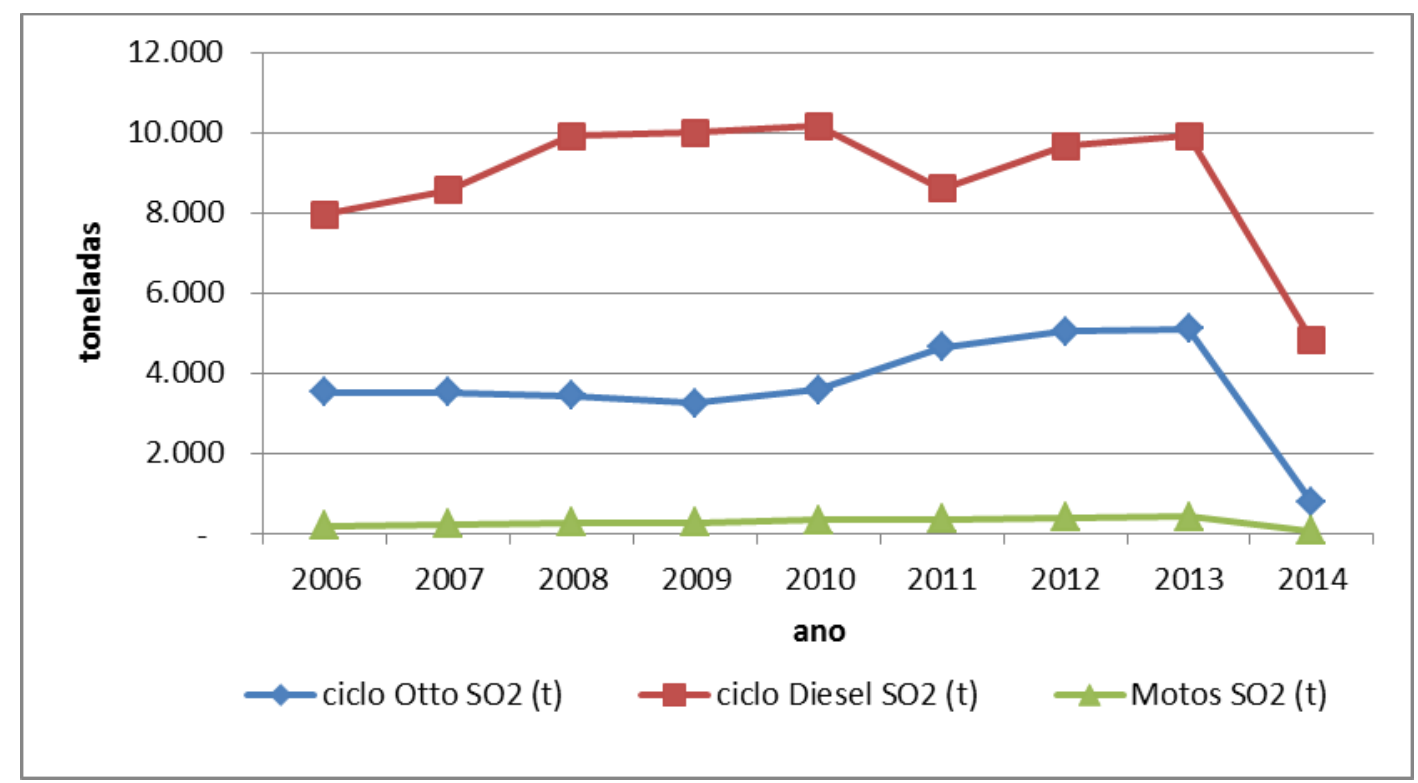

Deve-se ressaltar que as emissões de $\mathrm{SO}_{2}$ foram obtidas pela abordagem "topdown", que estão diretamente correlacionadas com o teor de enxofre dos combustíveis fósseis. A partir de janeiro de 2014, a gasolina passou a ter teor máximo de enxofre de $50 \mathrm{mg} / \mathrm{kg}$, o que resultou na redução observada na estimativa de emissão do $\mathrm{SO}_{2}$ dos veículos do ciclo Otto. No caso do diesel, as reduções recentes ocorreram no diesel de baixo teor de enxofre de 50 para $10 \mathrm{mg} / \mathrm{kg}$, em 2013, e a eliminação do diesel interior, de $1800 \mathrm{mg} / \mathrm{kg}$ a partir de janeiro de 2014 .

As estimativas de emissões de dióxido de enxofre são sempre calculadas empregando o teor máximo de enxofre presente nos combustíveis (gasolina $\mathrm{C}$ e óleo diesel). Assim é possível que a redução ocorrida de 2013 a 2014 não seja tão drástica, porém mais suave. Isso porque a queda do teor de enxofre máximo de 800 $\mathrm{mg} / \mathrm{kg}$ para $50 \mathrm{mg} / \mathrm{kg}$ na gasolina pode não representar os valores médios de concentração de enxofre realmente utilizados neste período.

As emissões de RCHO no Estado de São Paulo estão indicadas na figura 9, somente para veículos do ciclo Otto. Houve a redução de $33 \%$ nas emissões de $\mathrm{RCHO}$ de 2006 a 2014. 
Figura 9 - Evolução das emissões de RCHO no Estado de São Paulo, de 2006 a 2014.

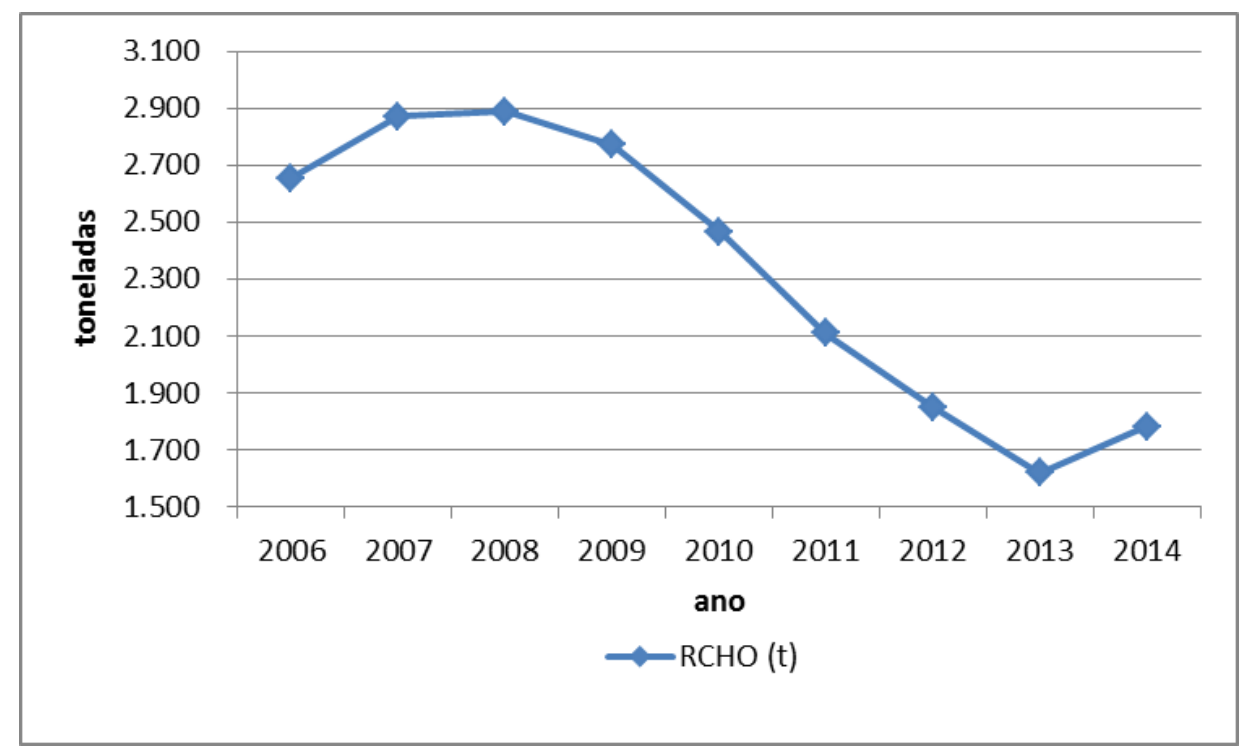

O aumento da emissão em 2014 deve-se ao aumento do uso do etanol em substituição à gasolina. $O$ fator de emissão de aldeídos quando os veículos utilizam etanol é maior do que quando estão utilizando gasolina.

As emissões de $\mathrm{CH}_{4}$ para o Estado de São Paulo são apresentadas na figura 10. Para os veículos do ciclo Otto, a abordagem usada para o cálculo das emissões foi a "bottom-up". Para os veículos do ciclo Diesel e motocicletas, a abordagem foi a "topdown" e foram utilizados os fatores de emissão recomendados pelo IPCC [3].

Houve a redução de $23 \%$ nas emissões totais de $\mathrm{CH}_{4}$ para os veículos do ciclo Otto e o aumento de $27 \%$ para o ciclo Diesel. As motocicletas tiveram a diminuição de 7\% nas emissões de $\mathrm{CH}_{4}$ no Estado de São Paulo, de 2006 a 2014. 
Figura 10 - Evolução das emissões de $\mathrm{CH}_{4}$ no Estado de São Paulo, de 2006 a 2014.

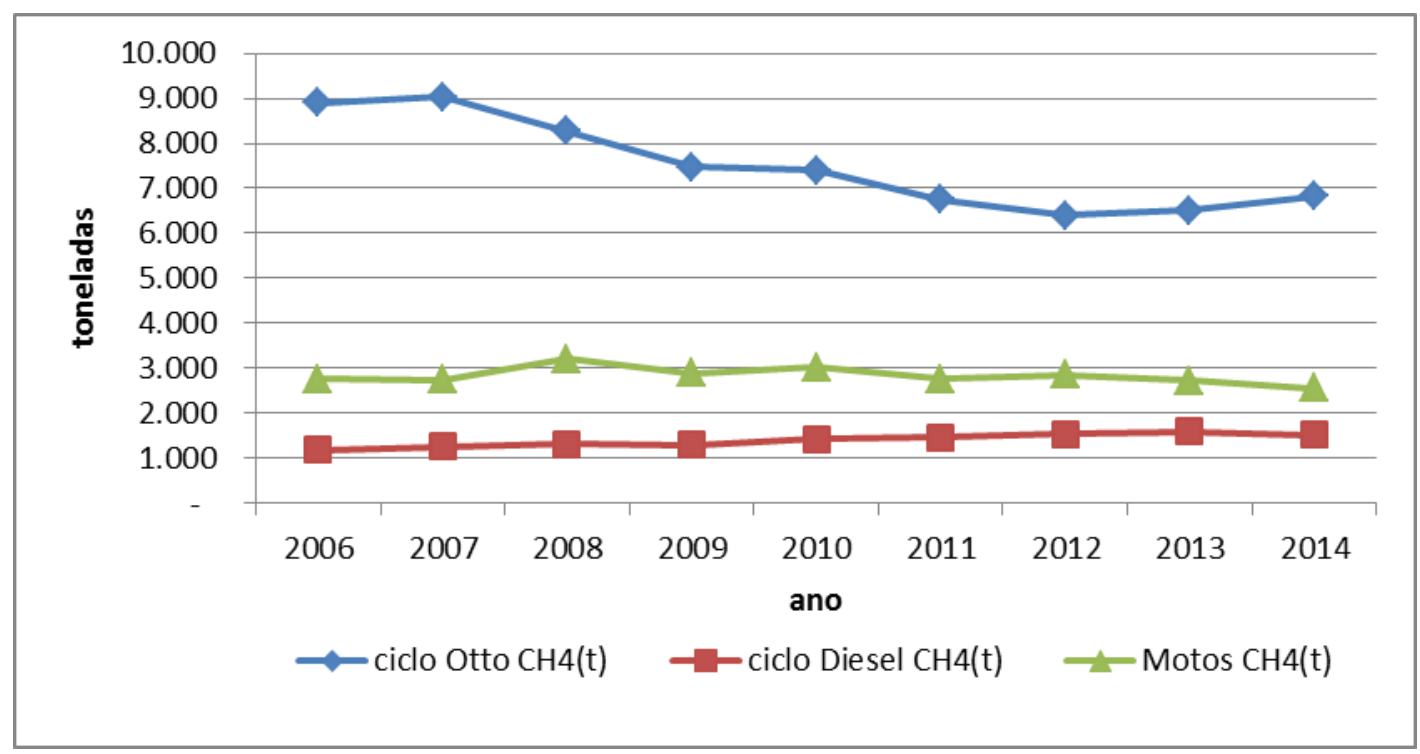

As emissões totais de $\mathrm{N}_{2} \mathrm{O}$ no Estado de São Paulo aumentaram 73\% de 2006 a 2014, de acordo com a figura 11, para os veículos do ciclo Otto. Houve também um aumento de $32 \%$ para os veículos do ciclo Diesel e de $50 \%$ para as motocicletas.

Figura 11 - Evolução das emissões de $\mathrm{N}_{2} \mathrm{O}$ no Estado de São Paulo, de 2006 a 2014.

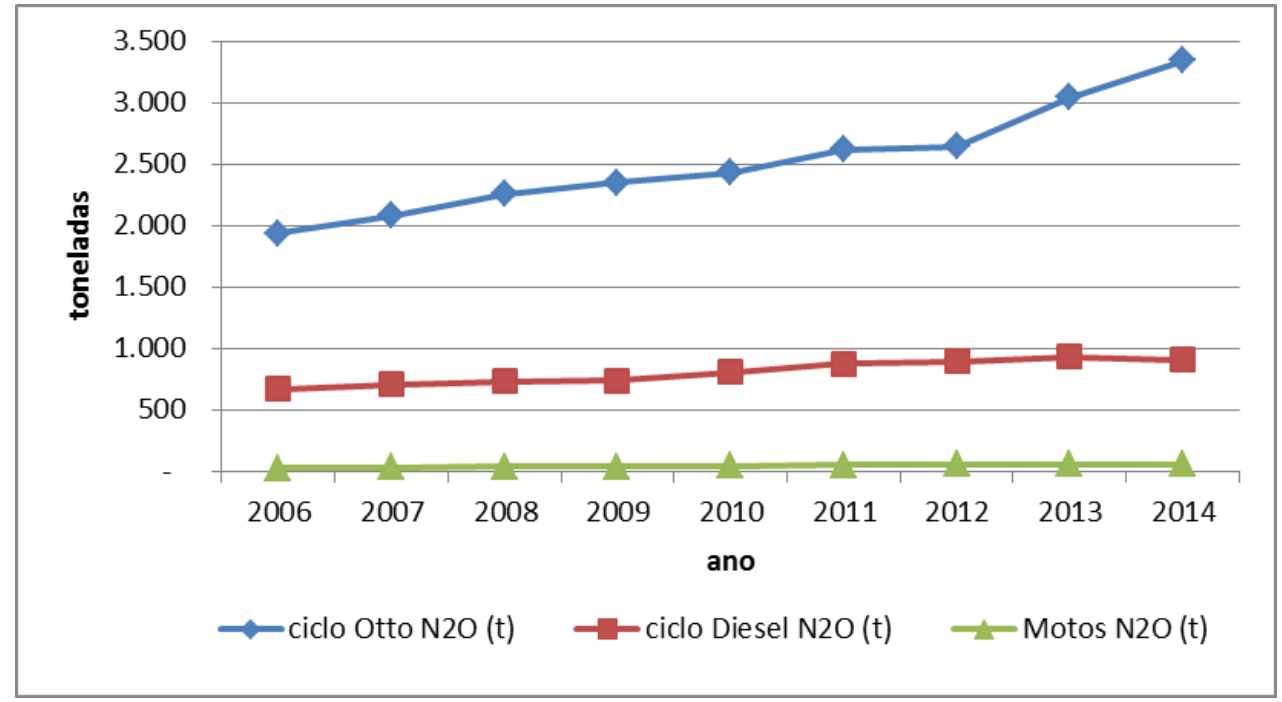


O aumento da emissão desse poluente pelos veículos do ciclo Otto em proporção maior que as categorias diesel e motos se dá pelo maior fator de emissão dos veículos equipados com catalisador. À medida que os veículos mais antigos e sem catalisador forem saindo da frota circulante, a tendência é de aumento. Quando toda a frota estiver equipada com esse dispositivo, a emissão deve se estabilizar. Devese ressaltar que o montante dessa emissão é pouco significativo frente à emissão total de GEE (Gases de Efeito Estufa).

As emissões de GEE foram obtidas utilizando o conceito de Potencial de Aquecimento Global (GWP), para os gases $\mathrm{CH}_{4}, \mathrm{~N}_{2} \mathrm{O}$ e $\mathrm{CO}_{2}$ em um horizonte de 100 anos [3], traduzidas no indicador $\mathrm{CO}_{2 \text { eq. }}$. Houve aumento de $46 \%$ nas emissões de $\mathrm{CO}_{2 \text { eq }}$ no Estado de São Paulo, de 2006 a 2014, como mostrado na figura 12.

Figura 12 - Evolução das emissões de $\mathrm{CO}_{2 e q}$, no Estado de São Paulo, de 2006 a 2014.

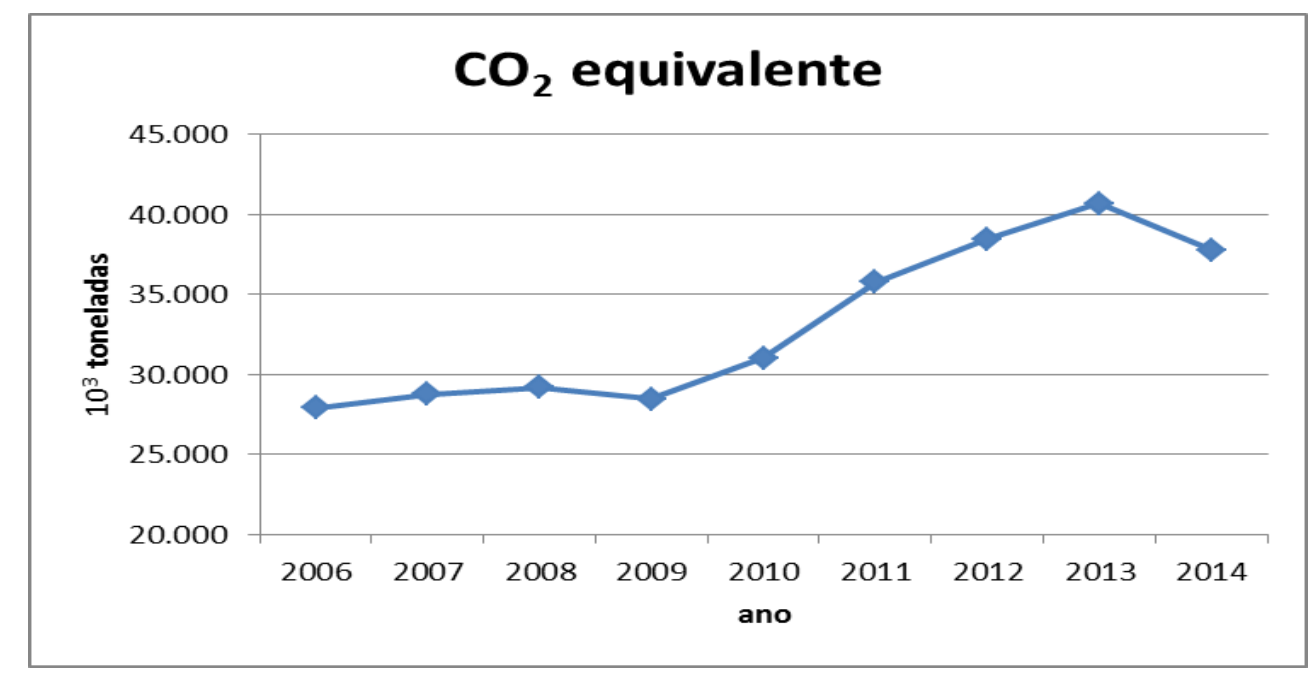

Essa evolução é motivada pelo aumento da frota circulante, pelo aumento no consumo de combustíveis e principalmente pela variação do consumo de etanol hidratado, substituído pelo consumo de gasolina $C$ nos veículos flex-fuel na maior parte do período em estudo. Em 2014 o fenômeno tem uma inflexão, pois subiu o consumo de etanol em detrimento ao uso da gasolina. 


\section{CONCLUSÃO}

Os resultados das estimativas das emissões veiculares no Estado de São Paulo confirmam que os veículos do ciclo Otto, seguidos pelas motos, têm maior influência nas emissões de $\mathrm{CO}$ e NMHC devido às características do motor e do número de veículos presentes na frota circulante do Estado de São Paulo. Os veículos do ciclo Diesel apresentam maior influência nas emissões de $\mathrm{NO}_{x}$ e MP.

As emissões veiculares de $\mathrm{CO}, \mathrm{NMHC}, \mathrm{NO}_{x}$ e MP têm se mantido estáveis no Estado de São Paulo, mesmo com o crescimento da frota circulante do ano de 2006 a 2014. Estes resultados podem ser atribuídos às ações e programas do PROCONVE/PROMOT.

A queda das emissões de $\mathrm{SO}_{2}$ é devida à redução do teor de enxofre dos combustíveis. Os processos de redução do teor de enxofre em curso levaram à redução das emissões, tanto para os veículos do ciclo Diesel quanto para os veículos movidos a gasolina.

As emissões de RCHO foram determinadas apenas para os veículos do ciclo Otto, pois ainda não há controle estabelecido para os veículos Diesel. As variações nas emissões deste poluente podem ser atribuídas à redução e o aumento do uso de etanol hidratado neste período.

As emissões de NMHC atribuídas ao abastecimento veicular têm crescido até corresponder a $22 \%$ das emissões de NMHC em 2014, devido ao aumento da frota circulante dos veículos do ciclo Otto e da sua utilização no Estado de São Paulo neste período.

Espera-se que pelas tendências, no ano de 2020 a emissão de abastecimento alcance $50 \%$ das emissões totais de $\mathrm{NMHC}$ e a partir daí passe a ser mais significativa que as emissões de escapamento e evaporativa. Dessa forma, faz-se necessário o desenvolvimento de sistemas de controle dessa emissão, de forma que os ganhos obtidos pela evolução do PROCONVE não sejam afetados pelas perdas durante $\mathrm{o}$ abastecimento.

$\mathrm{O}$ aumento e a queda posterior das emissões de $\mathrm{CO}_{2 e q}$ podem ser atribuídas ao aumento do consumo de combustíveis fósseis (Gasolina $\mathrm{C}$ e Diesel) e ao aumento do consumo de etanol hidratado especificamente em 2014. 


\section{REFERÊNCIAS}

[1] Ministério do Meio Ambiente. $\mathbf{1}^{\circ}$.Inventário Nacional de Emissões Atmosféricas por Veículos Automotores Rodoviários - Relatório Final, Brasília, 2011.

[2] Ministério do Meio Ambiente. Inventário Nacional de Emissões Atmosféricas por Veículos Automotores Rodoviários 2013 Ano Base 2012 - Relatório Final, Brasília, 2014.

[3] IPCC. 2006 IPCC Guidelines for National Greenhouse Gas Inventories. Prepared by the National Greenhouse Gas Inventories Programme, Eggleston H.S., Buendia L., Miwa K., Ngara T. and Tanabe K. (eds). Published:GES, Japan, 2006.

[4] Companhia Ambiental do Estado de São Paulo - CETESB. Relatório de Emissões Veiculares no Estado de São Paulo 2013, São Paulo, 2014.

[5] Associação Nacional dos Fabricantes de Veículos Automotores - ANFAVEA. Anuário da Indústria Automobilística Brasileira. dados relativos a 2013. Disponível em <http:Il www.anfavea.com.brlanuario.html> Acesso em 25/01/2015.

[6] Associação Brasileira dos Fabricantes de Motocicletas, Ciclomotores, Motonetas, Bicicletas e Similares - ABRACICLO. Anuário da Indústria Brasileira de Motociclos - 2013. Disponível em <http:॥ www.abraciclo.com.br> Acesso em 10/02/2015.

[7] Companhia Ambiental do Estado de São Paulo - CETESB. Curvas de intensidade de uso por tipo de veículo automotor da frota da cidade de São Paulo, São Paulo, 2014.

[8] SZWQRC, A; FARAH, E.L.; BRANCO, G.M.; BRANCO, F.C. Redução da Emissão Evaporativa do Veículo em Movimento e no Reabastecimento de Combustível. XXII Simpósio Internacional de Engenharia Automotiva, São Paulo, volume 1, número 2, 2014.

[9] Agência Nacional do Petróleo, Gás Natural e Biocombustíveis - ANP, Dados Estatísticos. Disponível em <http:॥ www.anp.gov.br> Acesso em 10/02/2015.

[10] IBAMA. Programa de controle da poluição do ar por veículos automotores - PROCONVE/PROMOT/IBAMA. 3ª ed. Brasília: Ibama/Diqua, 2011. Disponível em: $<$ http://www.ibama.gov.br/phocadownload/category/4?download=4792\%3Amanualportugues $>$. Acesso em: 05 set. 2014. 